\title{
Geleneksel Tekstil Ürün Tasarımlarının Değerlendirilmesi: Șanlıurfa Elbise Örtüleri
}

\author{
Prof. Dr. Hatice Feriha Akpınarlı ${ }^{1}$ \\ Arş. Gör. Dr. Pınar Arslan ${ }^{2 *}$
}

Geliş tarihi: 11.01 .2020

Kabul tarihi: 21.01.2020

\section{Atuf bilgisi: \\ IBAD Sosyal Bilimler Dergisi \\ Sayı: 6 Sayfa: 285-295}

Yıl: 2020 Dönem: Kış

This article was checked by Turnitin. Similarity Index 09\%

Bu makalede araştırma ve yayın etiğine uyulmuștur.

${ }^{1}$ Ankara Hacı Bayram Veli Üniversitesi, Türkiye, ferihaak@gmail.com, ORCID ID 0000-0001-9073-059X

${ }^{2}$ Ankara Hacı Bayram Veli Üniversitesi, Türkiye, pinar.arslan@hbv.edu.tr ORCID ID 0000-0002-6917-3642

* Sorumlu yazar
ÖZ

Kültür bir milletin kendine ait yaşamındaki parçalardan oluşturmaktadır. Gelenek, görenek, din, dil, tasarım, tekstil sanatları vb. olmak üzere farklı alanları kapsayan kültür kavramı, toplumsal değerleri yașatan ve geleceğe aktaran bir iletișim aracıdır. Çeşitli yöresel nitelikleri yansıtan zengin ve eşsiz özelliğe sahip geleneksel tekstil ürünleri (halı, kilim, ișleme, oya vb.) kültür aktarımını sağlamaktadır. Güneydoğu Anadolu Bölgesi'nde yer alan Şanlıurfa ilinde geleneksel tekstil ürünlerine rastlamak mümkündür. Kültürel kimliği yansıtan, desen tasarım açısından özgün olan Sanlıurfa elbise örtüleri kumaşı ve üzerindeki yüzey bezeme teknikleri ile tekstil ürünleri arasında yer almaktadır. Çalışmada yöntem olarak tarama yöntemi kullanılmıştır. Araştırmanın evrenini Güneydoğu Anadolu Bölgesi Şanlıurfa ilindeki geleneksel tekstil ürünleri oluştururken, araştırmanın örneklemi ise Şanlıurfa yöresine ait 14 adet elbise örtüsüdür. $\mathrm{Bu}$ çalıșmanın amacı Şanlıurfa elbise örtülerinin motif, kompozisyon, renk vb. olmak üzere tasarım özelliklerini incelemektir. Alan çalışması sonucunda Şanlıurfa yöresinde ulaşılabilen elbise örtü örneklerinin bitkisel, geometrik, figürlü, sembolik, nesneli, yazılı olmak üzere 6 farklı motif özelliğine sahip olduğu anlaşılmaktadır. Genellikle zemin rengi olarak beyaz renk, motiflerde ise genellikle canlı ve sıcak renkler tercih edilmektedir. Örtülerde kompozisyon olarak tam, ayna simetri ve birim raport kullanıldığı tespit edilmiştir.

Anahtar Kelimeler: Tekstil, tasarım, motif, kompozisyon, elbise örtüleri, geleneksel 


\title{
Evaluation of Traditional Textile Product Designs: Şanlıurfa Dress Covers
}

\author{
Prof. Dr. Hatice Feriha Akpınarlı ${ }^{1}$ \\ Res. Assist. Dr. Pınar Arslan ${ }^{2 *}$
}

First received: 11.01 .2020

Accepted: 21.01 .2020

\section{Citation:}

IBAD Journal of Social Sciences

Issue: 6

Pages: 285-295

Year: 2020

This article was checked by Turnitin. Similarity Index 09\%

1 Ankara Hacı Bayram Veli University, Turkey, ferihaak@gmail.com, ORCID ID 0000-0001-9073-059X

2 Ankara Hac1 Bayram Veli University, Turkey pinar.arslan@hbv.edu.tr

ORCID ID 0000-0002-6917-3642

* Corresponding Author

\begin{abstract}
Culture is made up of parts of a nation's own life. Traditions, customs, religion, language, design, textile arts etc. the concept of culture, which covers different areas, is a means of communication that perpetuates social values and transfers them to the future. Traditional textile products with rich and unique characteristics reflecting various local qualities (carpets, rugs, processing, oya etc.) provides cultural transfer. It is possible to find traditional textile products in Şanliurfa province, which is located in southeastern Anatolia region. Şanlıurfa dress covers, which reflect cultural identity and which are unique in terms of design with its fabric and their surface decoration techniques are among the textile products. Screening method was used as the method in the study. While traditional textile products in the province of Şanliurfa in the Southeastern Anatolia region constitute the universe of the research, the sample of the research is 14 dress covers belonging to the region of Şanliurfa. The aim of this study is to examine the design features that are motif, composition, color of Şanliurfa dress covers, etc. As a result of the field study, it is understood that the dress covers samples that can be reached in Şanliurfa region have 6 different motif features including floral, geometric, figural, symbolic, objective, written. White color is generally preferred as the ground color, while vivid and warm colors are generally preferred in motifs. It was determined that full, mirror symmetry and unit rapport were used as composition in the covers.
\end{abstract}

Keywords: Textile, design, motif, composition, dress covers, traditional 


\section{GíRIŞ}

Gelenek, görenek, adetler başta olmak üzere çeşitli unsurlar kültürün oluşmasında önemlidir. Tarih boyunca toplumlar, kendilerine has özelliklerini var edebilmek ve bu özellikleri sürdürebilmek amacıyla kendi öz benliklerini yansıtan yaşam tarzlarını korumaya çalışmaktadır. Bunun sonucunda toplumların zengin kültür anlayışı ortaya çıkmaktadır. Rathje (2009, s.35)'e göre kültür anlayışı toplumların homojenliğini sağlayan bir sistemi ifade etmektedir. Günümüzde ise Anadolu topraklarındaki medeniyetlerin etkisi ile kültür olgusu zenginleşmiş ve çoğalarak günümüze ulaşmıştır.

Kültür, ulusal ve uluslararası açıdan insanlığın sahip olduğu durumu ve süreci tanımlarken, entelektüel birikimin, yaratıcılığın, duygu, düşünce ve deneyimin çeşitli şekilde kaydedilerek belgelendiği ve belirli bir yaşam biçimini yansıtan bir kavramı tarif etmektedir (Williams, 1998, s. 48).

Somut olmayan kültürel miras, toplumlar arasındaki deneyimleri, faaliyetleri, kültürel birikimleri, değerleri, unsurları, öğretileri bir arada tutan köprüdür. Aynı zamanda toplumların, halkların, çeşitli grupların ortaya koymuş olduğu sanat, zanaat, tasarım, müzik, edebiyat, inanç vb. çeşitli alanları kapsamaktadır. Somut olmayan kültürel mirasın geçmişten geleceğe aktarımı konusunda yerel kültürlerin aslına uygun olarak yaşatılması ve bu konuda çalışmalara devam edilmesi gerekmektedir (Yakıcı, 2013, s. 31).

Somut Olmayan Kültürel Miras konusunda 2003 yılında Birleşmiş Milletler Eğitim, Bilim ve Kültür Teşkilatı (UNESCO) tarafindan Somut Olmayan Kültürel Mirasın Korunması Sözleşmesi kabul edilmiştir. Toplumların yaşam tarzlarında edinmiş oldukları bilgi, beceri, yap1, düşünce, uygulama vb. konuları oluşturan somut olmayan kültürel mirasın nesilden nesile aktarılmasında yaratıcılık, kültürel kimlik, sürdürebilirlik, farklı zamanların ve mekanların birbiri ile olan etkileşimi devam etmektedir. Somut Olmayan Kültürel Miras, adetler, gelenekler, gösteriler, masallar, ritüeller, eğlenceler, yemekler, halk inanışlarının yanında el sanatları geleneğini de kapsamaktadır (URL 1).

El sanatı somut bir ürüne dönüşmeden önce geleneklerden süzülen bilgi, anlayış, görgü, tasarım, stil, zaman gibi soyut boyutların etkisinde şekillenmektedir. El sanatı içindeki sanatsal emek el sanatçısının kişiliği ve becerisine dayanmaktadır. Diğer yandan el sanatçısının üretimlerini talep eden kullanıcıların kimlikleri ve algı dünyaları da elişinin sanatsallığı hakkında fikir verebilmektedir. Öte yandan, el sanatı yerel ve kolektif kimliği yansıtıcı role de sahiptir (Öter, 2010, s. 176).

El sanatları toplumların yaşam tarzı ile şekillenen, el emeği ile yapılan, dokuyanın, işleyenin kendini ifade etmesine imkan tanıyan, üretildiği dönemin özelliklerini ve kültürel kimliğini yansıtan ürünleri oluşturmaktadır. İnsanların kendileri için veya ekonomik fayda sağlamak amacıyla üretmesi vb. nedenlerine bağlı olarak el sanatları halı, kilim, kumaş dokuma, işleme, giyim-kuşam vb. olmak üzere farklı kullanım alanlarına sahiptir (Onuk ve Akpınarlı, 2005).

Geleneksel el sanatlarından özellikle evde yapılan el sanatlarının çarşı sanatlarına göre devamlılı̆g 1 yoğun olmasa da sürdürülmektedir, bunun en önemli nedeni çeyiz kültürünün devam etmesidir. Çeyiz geleneği, Türk kültürünün bütün devirlerde yöre, ekonomik durum fark etmeden her genç kız için yapılmış ve halen yapılmaktadır. Kırsal kesimlerde özellikle kız çocuğu doğduğunda başlayarak kilim, halı heybe, tuzluk, kumaş, işleme örtüler vb. aile büyükleri veya genç kızlar tarafından dokunur. Şehirlerde de yoğun olarak işleme, oya vb. yapılmaktadır. Yörelerindeki insanların ihtiyaçları, gelenekleri, yaşanan olaylar, bireylerin ve yaşadıkları toplumun duyguları, düşünceleri doğrultusunda çeyizler üretilmektedir. Çeyizlerin evde hazırlanan ürünleri geleneksel tekstil sanatlarını (dokuma, örgü, işleme vb.) içermektedir. 
Türk kültüründe çeyiz geleneği, çeyiz sandığı, çeyiz hazırlama, çeyiz serme,(çeyiz yazma, çeyiz asma) çeyiz götürme, çeyiz görme vb. adetler halen sürdürülmektedir.

Çeyizlerde ve geleneksel tekstil sanatlarında önemli olan ürünlerden biri olan elbise örtüleri Anadolu'nun birçok yöresinde yapılmış, kullanılmış halen kullanılmaktadır. Elbise örtüleri iki amaç için yapılmıştır. Elbiselerin üzerini örterek toz, kir, haşerelerden korumak ve çadırın, odanın duvarını süslemektir. Kırsal bölgelerde evlerde oda sayısı az olduğundan giyinilen odanın bir duvarına çakılan askı veya çiviler üzerine yerleştirilen giysiler üzerinde örtüler aynı zamanda bir tablo niteliğinde bezenmiştir. Örtülerin üzerinde yöreyi yansitan bezemeler o yöredeki insanların duygu, düşünce, yaşadıkları hüzün, mutluluk, çeşitli olaylar, bölgede yaşayan hayvanlar ve efsaneleri yansıtmaktadır. Anadolu'nun çeşitli bölgelerinde (Şanlıurfa, Kahramanmaraş, Mersin, Adana, Ankara, Çankırı, Muğla, Mardin, Gaziantep, Van) yapmış olduğumuz alan çalışmalarında elbise örtülerine rastlanmıştır. Ancak elbise örtüleri ile ilgili araştırmalara rastlanmamıştır. Bu nedenle en yoğun yapılan ve kullanılan illerimizden biri olan Şanlıurfa elbise örtülerini üzerinde çalışılmıştır.

Güneydoğu Anadolu Bölgesinde yer alan Şanlıurfa yöresinde keçeden kilime, saraçlıktan ağaç oymacılığına, bakırcılıktan kuyumculuğa olmak üzere çeşitli geleneksel el sanatları yapılmıştır ve günümüzde de devam etmektedir (Kürkçüoğlu, 2011, s. 173). Şanlıurfa'da ilinde hammaddesi lif olan el sanatları içerisinde yer alan elbise örtüleri geleneksel tekstil sanatı örnekleri arasında sayılmaktadır. "Geleneksel yaratmalar; sözlü, görsel, işitsel veya materyal olsun kendi şekil, yapı, içerik, işlev ve de yaratma ve aktarma özelliklerine sahiptir" (Ekici, 2008, s. 37). Şanlıurfa el sanatı geleneğini oluşturan bu örnekler kendi içerisinde yaratıcılık, motif, tasarım, renk, kompozisyon özellikleri ile geleneği aktarabilmektedir. Bu çalışma; kültürel kimliğimizi yansıtan geleneksel ürünlerin canlandırılması, belgelendirilmesi, kayıt altına alınarak gelecek kuşaklara taşınması amacını taşımaktadır. Bu bağlamda; geleneksel tekstil ürünlerinden biri olan Şanlıurfa elbise örtüleri motif, kompozisyon, renk açısından özellikleri incelenmiş ve ayrıntılı olarak açıklanmıştır.

\section{YÖNTEM}

Araştırmada tarama yöntemi kullanılmıştır. Araştırmanın evrenini Güneydoğu Anadolu Bölgesindeki geleneksel tekstil ürün tasarım özellikleri oluştururken, araştırma örneklemi ise Şanlıurfa yöresinde tespit edilen farklı özellikteki 14 adet elbise örtüsüdür. Araştırma kapsamında yörede alan çalışması yapılmıştır. Literatür taraması ve alan çalışması sonucunda elde edilen verilerin 1şığında tespit edilen geleneksel tekstil ürün örneklerini oluşturan elbise örtüleri motif, kompozisyon, renk açısından ayrıntılı olarak değerlendirilmiştir.

\section{ŞANLIURFA ELBİSE ÖRTÜLERININ TASARIM ÖZELLIKLERİ}

Şanlıurfa ili, kültür ve medeniyetin dünyaya yayıldığı bölge olarak kabul edilmektedir. Arkeolojik bulgulara göre 11.000 yıl önce Neolotik çağ insanları tarafindan kurulmuştur. Bu çağda yaşayanlar, avcı ve göçebe yaşamdan yerleşik düzene geçtikleri ilk köyleri kurarak, tarım faaliyetleri yaparak, ilk mimari eserleri meydana getirerek üretimi canlandırmıştır. Bu sayede Şanlıurfa, tarım ve mimarlık tarihi bakımından en eski şehirlerimizden biri olmuştur. Şanlıurfa, doğuyu batıya bağlayan ticari ve askeri yolların kesiştiği, kültür ve inançların toplandığı bir havzadır. Bunun en önemli kanıtları, dünyanın en eski heykeli, Göbekli Tepe'de ortaya çıkarılan dünyanın en eski tapınağı ve keşfedilmeyi bekleyen birçok yer bulunmaktadır. Şanlıurfa, aynı zamanda üç semavi dinin İbrahim peygamberde buluştuğu peygamberler şehridir.

Birçok kültürü bünyesinde barındıran Şanlıurfa, bu kültürlerin özelliklerini taşıdığından el sanatları konusunda da çok zengin bir yapıya sahiptir. Cülhacılık (kumaş dokumacılı̆̆ı), 
dokumacılık (halı, kilim) (Başaran ve Tağı, 2019, s. 161), işlemecilik, kazzazlık (ipek işlemeciliği), abacılık, keçecilik, çulculuk (semercilik), bakırcılık, kürkçülük, dabbaklık, tarakçılık, saraçlık, ağaç oymacılığı, taş süslemeciliği, altın - gümüş işlemeciliği (hışırlar), vb. el sanatları Şanlıurfa'da yapılmıştır ve bugün hala yapılmaktadır (Akpınarlı, Tozun, Başaran, Büyükyazıcı ve Ertürk, 2012, s. 7).

Araştırma kapsamında Şanlıurfa yöresinde tespit edilen birbirinden farklı tasarıma sahip elbise örtüsü örnekleri incelenmiştir. Elbise örtülerinde kumaş olarak Patiska veya ağartılmış Amerikan bezi kullanılmıştır. Yöredeki kaynak kişilerin belirtiğine göre ucuz çabuk yıkanabilen kolay temin ettikleri kumaşları ve beyaz rengi tercih ettiklerini belirtmişlerdir. Elbise örtülerinde iki şekil ile karşılaşılmıştır. Elbiseleri içine geçirilecek torba gibi dikilmiş örtüler veya düz olarak dikilmiş üst tarafından iplik ve lastik yeri yapılarak, büzgü ile elbiselerin üstünü örten örtülerdir. Örtülerin motif, kompozisyon ve renk özellikleri ayrıntılı olarak aşağıda yer almaktadır.
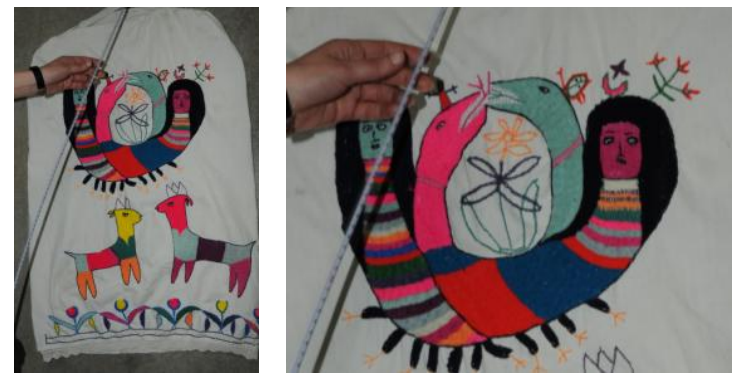

Görsel 1. Elbise örtüsü 1 (Akpınarlı v.d., 2012, s. 269)

Örnek 1'deki elbise örtüsünde; beyaz zemin üzerinde bitkisel bezemelerden lale, dal, yaprak motiflerinin, figürlü bezemelerden keçi motiflerinin, sembolik bezemelerden şahmeran motifinin hakim olduğu görülmektedir. Kompozisyon açısından değerlendirildiğinde; tam rapor düzenine sahip birbirine karşılıklı bakan keçi motiflerinden ve keçi motiflerinin alt kısmında bordür şeklinde lale, dal, yaprak motifleri yer almaktadır. Kumaşın zemininde beyaz renk hakim, motiflerde ise açık mavi, pembe, turuncu, sarı, siyah, açık yeşil, koyu yeşil, mor, koyu mavi renkler kullanılmaktadır. Motiflerin yapımında çin iğnesi ve iğne ardı işleme teknikleri, uç kısımda ise tığ örücülüğü dantel yer almıştır.
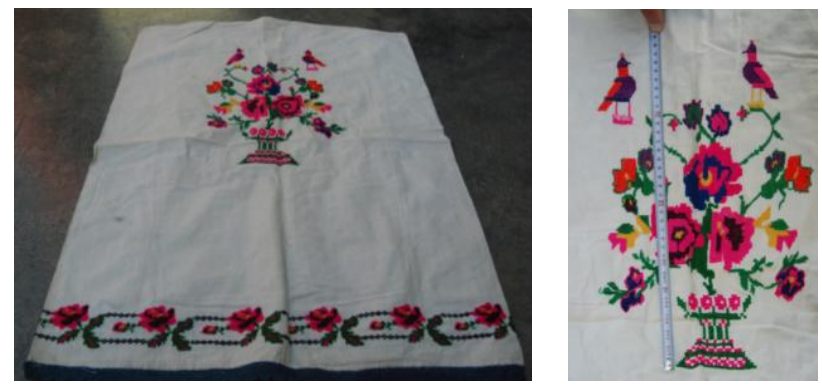

Görsel 2. Elbise örtüsü 2 (H. F. Akpınarlı fotoğraf arşivi, 2010)

Örnek 2'teki elbise örtüsünde; beyaz zemin üzerinde bitkisel bezemelerden çiçek, dal, yaprak motiflerinin, geometrik bezemelerden üçgen ve düz çizgi motiflerinin, nesneli bezemelerden vazo motifinin, figürlü bezemelerden kuş motiflerinin hakim olduğu görülmektedir. Kompozisyon açısından değerlendirildiğinde; yüzeyde ayna simetri rapor düzeni kullanılmaktadır. Dal üzerinde gül motifleri bordür şeklinde elbise örtüsünün alt kısmında yer almıştır. Kumaşın ortasında vazoda çiçek motifleri, vazonun üst kısmında kuş motifleri yer almaktadır. Kumaşın zemininde beyaz renk hakim, motiflerde ise pembe, siyah, koyu yeşil, açık yeşil, mor, lacivert, kırmızı renkler ve işleme tekniklerinden kanaviçe kullanılmıştır. 


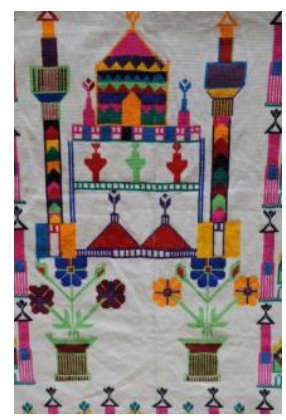

Görsel 3. Elbise örtüsü 3 (Akpınarlı v.d., 2012, s. 253)

Örnek 3'teki elbise örtüsünde; beyaz zemin üzerinde bitkisel bezemelerden çiçek, dal, yaprak motiflerinin, nesneli bezemelerden cami, minare, vazo motiflerinin hakim olduğu görülmektedir. Kompozisyon açısından değerlendirildiğinde; yüzeyde ayna simetri rapor düzeni kullanılmaktadır. Tasarımda cami motifi üst kısımda, vazoda çiçek dal, yaprak motifleri alt kısımda ve sağ ve sol tarafta karşılıklı minareler yer almaktadır. Kumaşın zemininde beyaz renk hakim, motiflerde ise açık yeşil, kırmızı, koyu mavi, açık mavi, turuncu, pembe, koyu yeşil, siyah, sarı renkler ve işleme tekniklerinden kaneviçe kullanılmıştır.
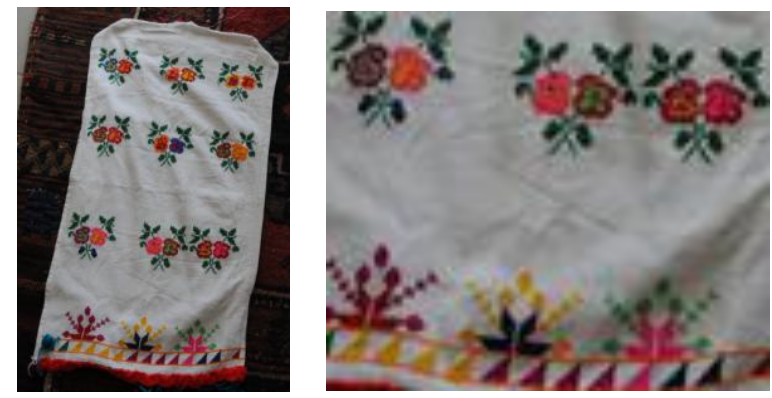

Görsel 4. Elbise örtüsü 4 (Akpınarlı v.d., 2012, s. 254)

Örnek 4'teki elbise örtüsünde; beyaz zemin üzerinde bitkisel bezemelerden çiçek, dal, yaprak, tomurcuk motiflerinin, geometrik bezemelerden üçgen ve düz çizgi motiflerinin hakim olduğu görülmektedir. Kompozisyon açısından değerlendirildiğinde; yüzeyde tam rapor düzeni kullanılmaktadır. Kumaşın alt kısmında iki düz çizgi arasında üçgen motifleri bordür şeklinde, bordürün üzerindeki çiçek, dal, yaprak, tomurcuk motifleri ise yüzeyde serbest düzende yer almaktadır. Kumaşın zemininde beyaz renk hakim, motiflerde ise sarı, kırmızı, pembe, siyah, koyu yeşil, açık yeşil, lacivert, turuncu renkler ve işleme tekniklerinden kaneviçe kullanılmıştır.
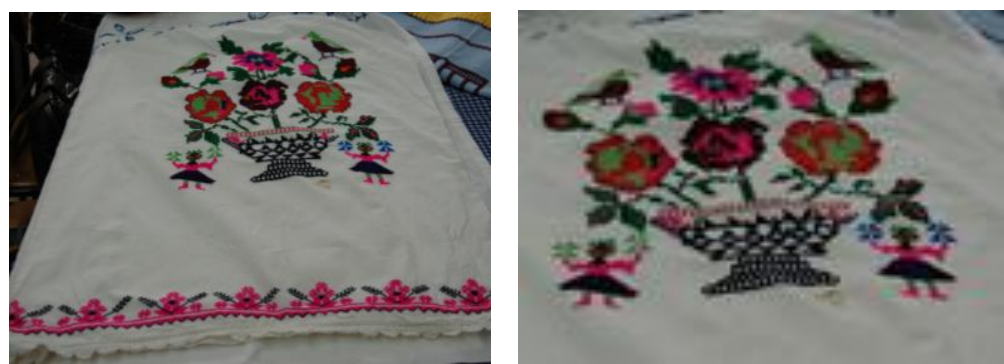

Görsel 5. Elbise örtüsü 5 (Akpınarlı v.d., 2012, s. 255)

Örnek 5'teki elbise örtüsünde; beyaz zemin üzerinde bitkisel bezemelerden çiçek, dal, yaprak motiflerinin, geometrik bezemelerden üçgen ve düz çizgi motiflerinin, nesneli bezemelerden vazo motifinin, figürlü bezemelerden insan ve kuş motiflerinin hakim olduğu görülmektedir. Kompozisyon açısından değerlendirildiğinde; yüzeyde ayna simetri rapor düzeni kullanılmaktadır. İki düz çizgi arasında üçgen motifleri bordür şeklinde kumaşın alt kısmında 
yer alırken, bordürün üzerinde çiçek, dal, yaprak motifleri görülmektedir. Kumaşın ortasında vazoda çiçek motifleri, vazo motifinin alt kısmında insan figürleri yer alırken, vazonun üst kısmında ise kuş motifleri yer almaktadır. Kumaşın zemininde beyaz renk hakim, motiflerde ise pembe, siyah, koyu yeşil, açık yeşil, koyu mavi, kahverengi, kırmızı renkler ve işleme tekniklerinden kanaviçe kullanılmıştır.
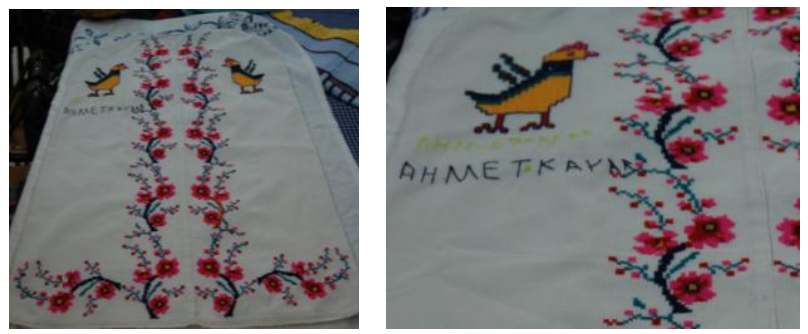

Görsel 6. Elbise örtüsü 6 (Akpınarlı v.d., 2012, s. 256)

Örnek 6'daki elbise örtüsünde; beyaz zemin üzerinde bitkisel bezemelerden çiçek, dal, tomurcuk motiflerinin, figürlü bezemelerden kuş motiflerinin hakim olduğu görülmektedir. Kompozisyon açısından değerlendirildiğinde; yüzeyde ayna simetri rapor düzeni kullanılmaktadır. Diyagonal olarak yerleştirilen çiçek, dal, tomurcuk motifleri karşılıklı olarak birbirine bakan müjdeli haber ve özgürlük sembolü kuş motifleri görülmektedir. Yazılı bezeme olarak örtünün sahibinin ismi işlenmiştir. Çoğunlukla damat giysileri için yapılan örtülerde isim yazıldığı belirtilmiştir. Kumaşın zemininde beyaz renk hakim, motiflerde ise pembe, siyah, koyu yeşil, kırmızı, turuncu, kahverengi renkler kullanılmaktadır. Motifler kaneviçe ve iğne ardı işleme tekniği ile yapılmıştır.
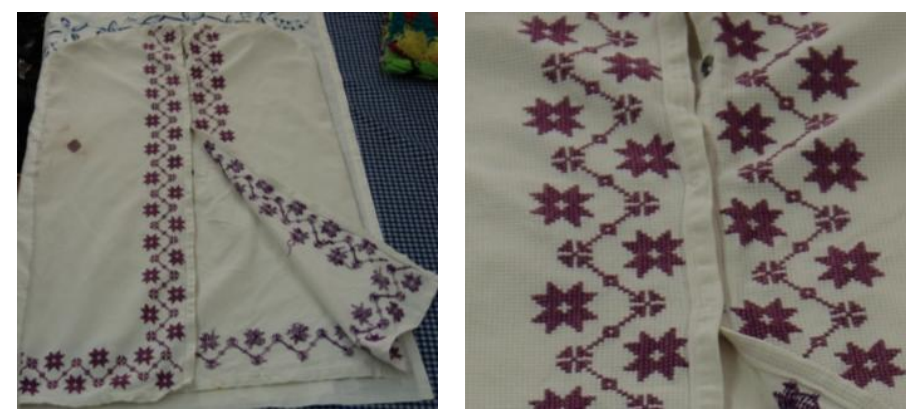

Görsel 7. Elbise örtüsü 7 (Akpınarlı v.d., 2012, s. 257)

Örnek 7'deki elbise örtüsünde; beyaz zemin üzerinde bitkisel bezemelerden çiçek motiflerinin hakim olduğu görülmektedir. Kompozisyon açısından değerlendirildiğinde; yüzeyde ayna simetri rapor düzeni kullanılmaktadır. Kumaşın kenarlarında bordür şeklinde yer alan motifler bulunmaktadır. Kumaşın zemininde beyaz, motiflerde ise mor renk tercih edilmiştir. Elbise torbası ön ortasından açık şekilde tasarlanmıştır. İşleme tekniklerinden kaneviçe kullanılmıştır.
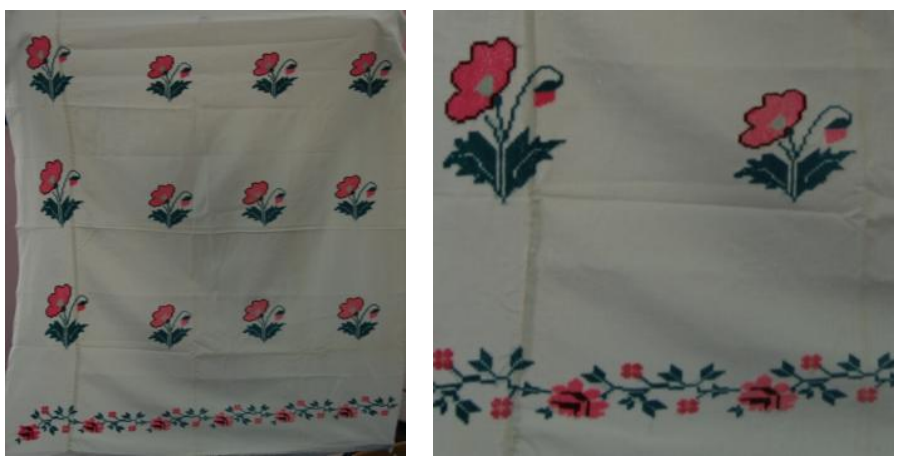

Görsel 8. Elbise örtüsü 8 (Akpınarlı v.d., 2012, s. 259) 
Örnek 8'deki elbise örtüsünde; beyaz zemin üzerinde bitkisel bezemelerden çiçek, dal, yaprak motiflerinin hakim olduğu görülmektedir. Kompozisyon açısından değerlendirildiğinde; yüzeyde tam rapor düzeni kullanılmaktadır. Kumaşın üst kısmında birim olarak yerleşmiş ve alt kısmında bordür şeklinde yer alan çiçek, dal, yaprak motifleri bulunmaktadır. Kumaşın zemininde beyaz renk hakim, motiflerde ise pembe, siyah, koyu yeşil, açık yeşil renkler kullanılmaktadır. Motifler işleme tekniklerinden kaneviçe ile yapılmıştır.
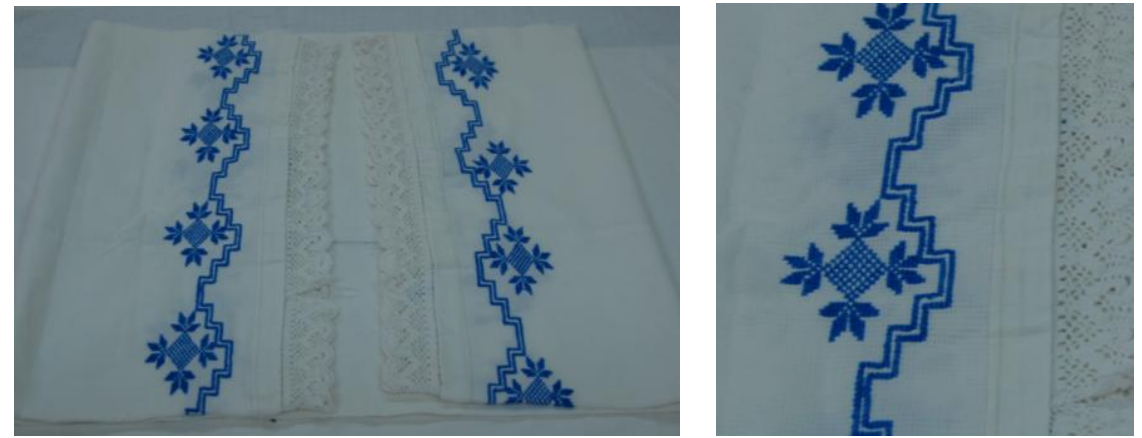

Görsel 9. Elbise örtüsü 9 (Akpınarl1 v.d., 2012, s. 260)

Örnek 9'daki elbise örtüsünde; beyaz zemin üzerinde bitkisel bezemelerden çiçek motiflerinin, geometrik bezemelerden dörtgen, zikzak çizgi motiflerinin hakim olduğu görülmektedir. Kompozisyon açısından değerlendirildiğinde; yüzeyde tam rapor düzeni kullanılmaktadır. Kumaşın üst ve alt kısmında bordür şeklinde yer alan zikzak motiflerinin ve ortasında dörtgen bulunan çiçek motifleri görülmektedir. Kumaşın zemininde beyaz renk hakim, motiflerde ise koyu mavi renk kullanılmaktadır. İşleme tekniklerinden kaneviçe kullanılmıştır.
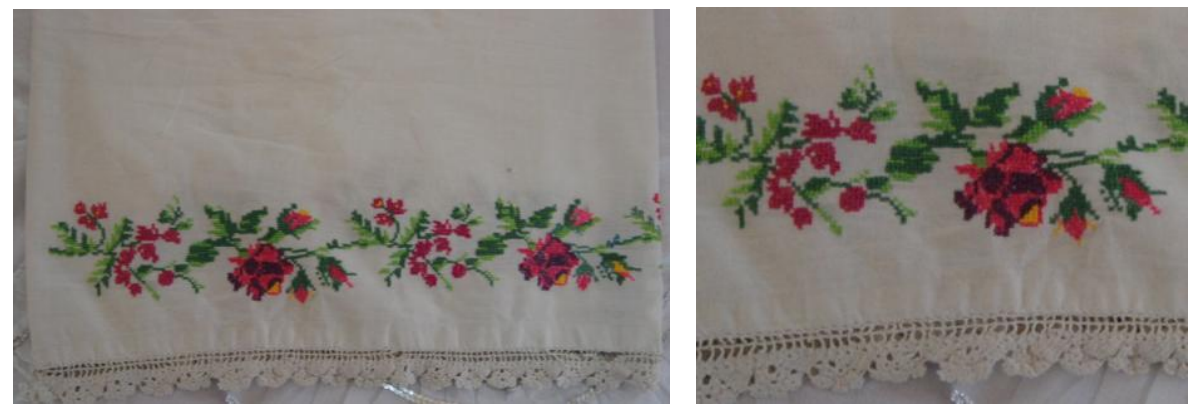

Görsel 10. Elbise örtüsü 10 (Akpınarlı v.d., 2012, s. 264)

Örnek 10'daki elbise örtüsünde; beyaz zemin üzerinde bitkisel bezemelerden çiçek, dal, yaprak, tomurcuk motiflerinin hakim olduğu görülmektedir. Kompozisyon açısından değerlendirildiğinde; yüzeyde tam rapor düzeni kullanılmaktadır. Kumaşın alt kısmında bordür şeklinde yer alan çiçek dal, yaprak, tomurcuk motifleri görülmektedir. Kumaşın zemininde beyaz renk hakim, motiflerde ise pembe, koyu yeşil, açık yeşil, sarı, mor renkler kullanılmaktadır. Motifler kanaviçe tekniği ile yapılmıştır. Uç kısmında tı̆̆ örücülüğü dantel kullanılmıştır.
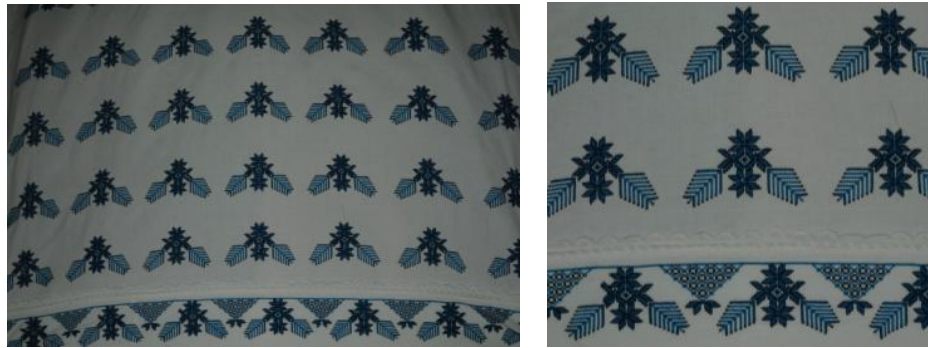

Görsel 11. Elbise örtüsü 11 (Akpınarlı v.d., 2012, s. 270) 
Örnek 11'deki elbise örtüsünde; beyaz zemin üzerinde bitkisel bezemelerden lale, çiçek, dal, yaprak motiflerinin, geometrik bezemelerden daire, düz çizgi ve üçgen motiflerinin hakim olduğu görülmektedir. Kompozisyon açısından değerlendirildiğinde; yüzeyde birim rapor düzeni kullanılmaktadır. Kumaşın üst kısmında bordür şeklinde yer alan lale, çiçek, dal, yaprak motiflerinin arasında üçgen motifler görülmektedir. Kumaşın zemininde beyaz renk hakim, motiflerde ise koyu mavi, açık mavi, siyah, kahverengi, sarı renkler kullanılmaktadır. İşleme tekniklerinden kaneviçe kullanılmıştır.
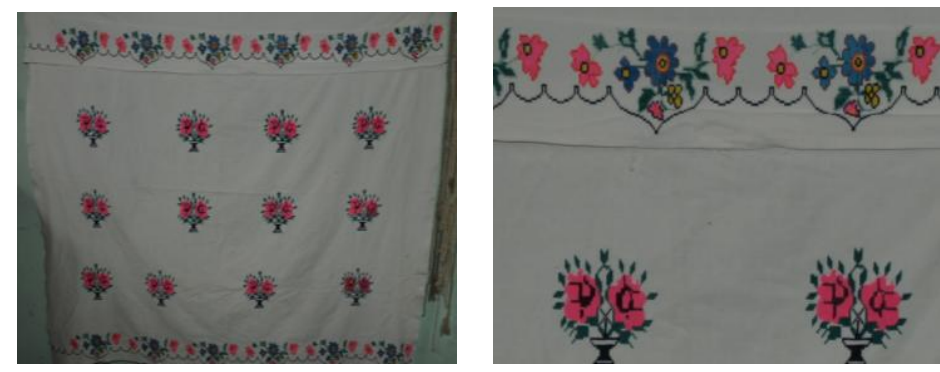

Görsel 12. Elbise örtüsü 12 (Akpınarlı v.d., 2012, s. 271)

Örnek 12'deki elbise örtüsünde; beyaz zemin üzerinde bitkisel bezemelerden çiçek, dal, yaprak motiflerinin, geometrik motiflerden diyagonal çizgilerin, nesneli bezemelerden vazo motiflerinin hakim olduğu görülmektedir. Kompozisyon açısından değerlendirildiğinde; yüzeyde tam rapor düzeni kullanılmaktadır. Kumaşın üst ve alt kısmında bordür şeklinde yer alan çiçek, dal, yaprak motiflerinin arasında diyagonal çizgiler görülmektedir. Aynı zamanda kumaşın yüzeyinde serbest düzende çiçek motifleri yer almaktadır. Kumaşın zemininde beyaz renk hakim, motiflerde ise pembe, koyu yeşil, siyah, açık yeşil, mor, koyu mavi, sarı renkler kullanılmaktadır. İşleme tekniklerinden kaneviçe kullanılmıştır.
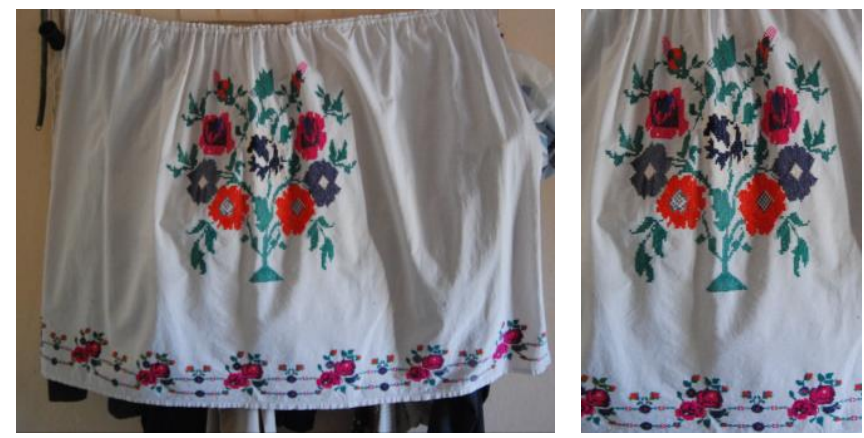

Görsel 13. Elbise örtüsü 13 (Akpınarlı v.d., 2012, s. 274)

Örnek 13’teki elbise örtüsünde; beyaz zemin üzerinde bitkisel bezemelerden gül, çiçek, dal, yaprak motiflerinin, nesneli bezemelerden vazo motifinin hakim olduğu görülmektedir. Kompozisyon açısından değerlendirildiğinde; yüzeyde tam rapor düzeni kullanılmaktadır. Kumaşın alt kısmında bordür şeklinde yer alan birbiri arasından geçen çiçek, dal, yaprak motifleri görülmektedir. Kumaşın zemininde beyaz renk hakim, motiflerde ise pembe, koyu mavi, mor, turuncu, koyu yeşil, açık yeşil renkler kullanılmaktadır. İşleme tekniklerinden kaneviçe kullanılmıştır. 

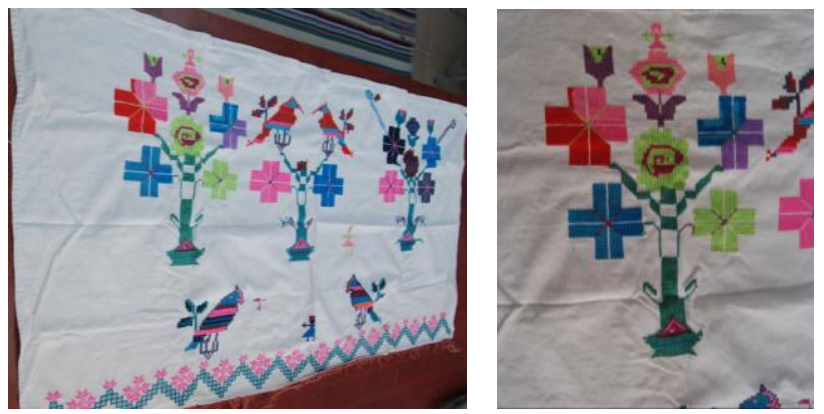

Görsel 14. Elbise örtüsü 13 (H. F. Akpınarlı fotoğraf arşivi, 2012)

Örnek 14'deki elbise örtüsünde; beyaz patiska kumaş üzerinde bitkisel, figürlü ve nesneli bezemeler görülmektedir. Saksı içinde geometrik hatlı çiçekler ve karşılıklı kuş ortasında insan figürü motifleri işlenmiştir. Motiflerde kırmızı, koyu mavi, turkuaz, pembe, mor, eflatun, açık yeşil, koyu yeşil ve sarı kullanılmıştır. Alt kısımda zikzak çizgilerin içinde bitkisel bezemelerden oluşan bordür yerleştirilmiştir. İşleme tekniklerinden kaneviçe kullanılmıştır.

İncelenen 14 adet elbise örtülerini değerlendirdiğimizde; Elbise örtülerinin \%100 zeminde beyaz patiska kumaş kullanılmıştır. Yoğun olarak koyu yeşil, açık yeşil ve pembe renklerin kullanıldığı bunu sırasıyla siyah, koyu mavi, sarı, mor, kırmızı, turuncu, kahverengi, açık mavi, lacivert, turkuaz, eflatun renkler takip etmektedir. Bezeme olarak en yoğun bitkisel bezeme kullanılmış bunu nesneli, figürlü, sembolik ve yazılı bezemeler takip etmiştir. Bitkisel bezemelerden çiçek, gül, dal ve yaprak motifleri; figürlü bezemelerde yoğunluk sirasıyla kuş, insan, şahmeran, keçi motifleri; nesneli bezemelerde yoğun saksı motifi, cami ve minare motifleri; yazılı bezemede ise isim kullanılmıştır. Kompozisyonda ise yoğunluk sırasıyla tam raport, ayna simetri ve birim raporttur. Teknik açısından işleme ve tı̆̆ örücülüğü kullanılmış, işleme olarak en yoğun kanaviçe kullanılmış, çin iğnesi, sarma ve sap işi teknikleri de yapılmıştır Akpınarlı vd. (2012, s.249) Şanlıurfa El Sanatlarına ilişkin yayında örtülerin motif, kompozisyon özelliklerinden bahsetmekte ve bitkisel, figürlü, sembolik, nesneli bezemelerin işlendiğini, motiflerin çeşitli kompozisyon düzenine sahip olduğunu açıklamışlardır.

\section{SONUÇ}

Elbise örtülerinin yörede ve Anadolu'daki kırsal bölgelerde kullanım özellikleri birbirine benzemektedir. Aynı zamanda çadır kültürü ve konargöçer yaşam şartlarına bağlı ortaya çıkmış bir üründür. Çadırın veya odaların duvarına asılan elbiseleri toz, haşare vb. korumak için elbiselerin üzerine örtülen düz veya kılıf şeklinde olan elbise içine konularak asılan örtülerdir. Örtü üzerindeki motiflerde nazardan korumak ve kötülüklerden korumak amaciyla şahmeran, kuş, çeşitli çiçekler mavi renkli iplikler kullanılmıştır. Bu özellikleri ile kültürel inançlarımızın birçok yönünü yansıtan kültürel miras unsurları olarak karşımıza çıkmaktadır. Yerleşik düzene geçiş çadır hayatının kullanılmaması, odalarda elbiselerin duvarlara değil dolapların içine asılmasından dolayı elbise örtülerinin kullanımı azalmıştır. Ancak Şanlıurfa ili köylerinde halen kullanılmaya devam edilmektedir.

Yöredeki elbise örtülerinde bitkisel bezemeler başta olmak üzere çeşitli bezeme türleri kullanılmaktadır. İnançların etkisiyle duygu ve düşüncelerini motiflere yansıtan yöre insanı nazar inancı ile bütünleşen sembolleri elbise örtülerine yansıtmıştır. Duvara asılan elbise örtülerinin eve canlılık ve güzellik katması için tablo gibi bezenmiştir. Örtülerde kullanılan renkler incelendiğinde; genellikle sıcak renklerin tercih edildiği, kompozisyonlarda ise genellikle tam raport ve ayna simetri raport kullanıldığı görülmektedir. Ülke kültürümüzün tanıtılması ve geleneksel tekstil sanatlarının ürünlerindeki kültürel kimliğimizi efsanelerimizi anlatan sembollerin, motiflerin incelenmesi, belgelenmesi yeni kuşaklara tanıtılması çalışmaları ilgili kuruluşlar, kurumlar ve konu uzmanları tarafından yapılmalıdır. 


\section{KAYNAKÇA}

Akpınarlı, H. F., Tozun, H., Başaran, F. N., Büyükyazıcı, M. ve Ertürk, Y. P. (2012). Şanlıurfa el sanatları ve sözlü kültür malzemeleri. Şanlıurfa: Şurkav Yayınları.

Başaran, F. N. ve Tağı, S. (2019). Şanlıurfa kilim dokumaları. Hasan Çiftçi, Nurlan Akhmetov (Ed.), 4. Uluslararası Gap Sosyal Bilimler Kongresi (s. 158-171) içinde. Şanlıurfa.

Ekici, M. (2008). Geleneksel kültürü güncellemek üzerine bir değerlendirme. Milli Folklor, 20(80), s. 33-38.

Kürkçüoğlu, S. (2011). Şanlıurfa el sanatlarının turizmdeki yeri ve önemi. H. Feriha Akpınarlı, Hatice Tozun, Fatma Nur Başaran, Meral Büyükyazıcı (Ed.), Uluslararası Türk ve Dünya Kültüründe Şanlıurfa Sempozyumu (s. 165- 181) içinde. Şanlıurfa.

Onuk, T. ve Akpınarlı, H. F. (2005). Cumhuriyetten günümüze el sanatlarının doğuşu, gelişimi, sosyal kültürel eğitim ve ekonomik ilişkileri bakımından bugünkü durumu ve geleceği. V. Türk Kültürü Kongresi Cumhuriyetten Günümüze Türk Kültürünün Dünü, Bugünü ve Geleceği (s. 27-60) içinde. Ankara.

Öter, Z. (2010). Türk el sanatlarının kültür turizmi bağlamında değerlendirilmesi. Milli Folklor, 22(86), s. 174-185.

Rathje, S. (2009). The definition of culture - an application-oriented overhaul. Interculture Journal, 35-58.

URL 1: 30 Aralık 2019 tarihinde https:://aregem.ktb.gov.tr/TR-50837/somut-olmayan-kulturelmirasin-korunmasi-sozlesmesi-hak-.html adresinden erişildi.

Williams, R. (1998). The analysis of culture. John Storey (Ed.). Cultural Theory and Popular Culture A Reader (s. 48-56) içinde. Athens: The University of Georgia Press.

Yakıcı, A. (2013). Bilimsel kuruluşlarda somut olmayan kültürel mirasın korunmasına yönelik çalışmalar. M. Öcal Oğuz, Evrim Ölçer Özünel, Selcan Gürçayır Teke (Ed.). Somut Olmayan Kültürel Mirasın Geleceği Türkiye Deneyimi (s. 31-40) içinde. Ankara: Grafiker Ltd. Şti. 